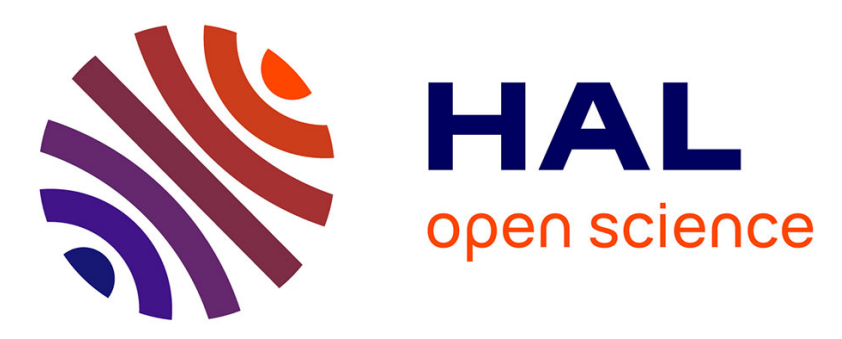

\title{
Uneven-aged management options to promote forest resilience for climate change adaptation: effects of group selection and harvesting intensity
}

Valentine Lafond, Guillaume Lagarrigues, Thomas Cordonnier, Benoît Courbaud

\section{To cite this version:}

Valentine Lafond, Guillaume Lagarrigues, Thomas Cordonnier, Benoît Courbaud. Uneven-aged management options to promote forest resilience for climate change adaptation: effects of group selection and harvesting intensity. Annals of Forest Science, 2014, 71 (2), pp.173 - 186. 10.1007/s13595-0130291-y . hal-01098407

\section{HAL Id: hal-01098407 https://hal.science/hal-01098407}

Submitted on 24 Dec 2014

HAL is a multi-disciplinary open access archive for the deposit and dissemination of scientific research documents, whether they are published or not. The documents may come from teaching and research institutions in France or abroad, or from public or private research centers.
L'archive ouverte pluridisciplinaire HAL, est destinée au dépôt et à la diffusion de documents scientifiques de niveau recherche, publiés ou non, émanant des établissements d'enseignement et de recherche français ou étrangers, des laboratoires publics ou privés. 


\title{
Uneven-aged management options to promote forest resilience for climate change adaptation: effects of group selection and harvesting intensity
}

\author{
Valentine Lafond • Guillaume Lagarrigues • \\ Thomas Cordonnier • Benoît Courbaud
}

Received: 4 November 2012 / Accepted: 15 April 2013 / Published online: 16 May 2013

(C) INRA and Springer-Verlag France 2013

\begin{abstract}
- Context Climate change is expected to increase forest vulnerability through disturbances such as windstorms and droughts. Forest managers are therefore investigating strategies to increase forest resistance and resilience, especially by promoting uneven-aged and mixed forests through group selection, and by reducing stand stocking and large trees proportion. However, there is little information on the longterm impacts of these two practices.

- Aims The objectives of this study were (1) to develop an original silviculture algorithm designed for uneven-aged management and (2) to use it to assess the effects of the abovementioned management methods in long-term simulations.

- Methods We simulated individual and group selection techniques in order to study the effects of group size, harvesting intensity and their interactions on wood production, stand heterogeneity, and regeneration in mountain spruce-fir forests. We used the spatially explicit individual-based forest model Samsara2 to simulate forest dynamics.
\end{abstract}

\section{Handling Editor: Gilbert Aussenac}

Contribution of the co-authors V. Lafond and G. Lagarrigues both carried out the study and wrote this paper. G. Lagarrigues developed the latest version of the algorithm and implemented it on the Capsis4 platform during his Master training period, under supervision of $\mathrm{V}$. Lafond. The whole work has been conducted under supervision of $\mathrm{T}$. Cordonnier and B. Courbaud, who contributed to algorithm development, to experiment design, and revised the manuscript.

Valentine LAFOND and Guillaume LAGARRIGUES contributed equally to the study.

Electronic supplementary material The online version of this article (doi:10.1007/s13595-013-0291-y) contains supplementary material, which is available to authorized users.

V. Lafond $(\bowtie) \cdot \mathrm{G}$. Lagarrigues $\cdot$ T. Cordonnier $\cdot$ B. Courbaud Irstea-EMGR, 2 rue de la Papeterie, BP 76,

38402 Saint-Martin-d'Hères Cedex, France

e-mail: valentine.lafond@irstea.fr
- Results Our simulation results confirmed the positive effect of group selection practices on structure diversity and regeneration but not on spruce maintenance. Increasing harvesting intensity enabled forest destocking but decreased structure diversity and led to non-sustained yields for the most intensive scenarios.

- Conclusion As adaptation measure, we thus recommend moderate group selection harvesting creating $500 \mathrm{~m}^{2}$ gaps.

Keywords Forest resilience · Climate change adaptation . Uneven-aged selection forest . Thinning and harvesting algorithm $\cdot$ Forest dynamics modeling

\section{Introduction}

Climate change is expected to increase the vulnerability of forest ecosystems in the Alps (Seidl et al. 2011b), through higher exposure to natural disturbances and stresses, especially storms and droughts (Beniston et al. 2007). Uncertainty regarding the natural adaptation capacity of forests to changing environment requires the development of specific measures in forest management (Jactel et al. 2009; Seidl et al. 2011a), so as to improve forest resistance and resilience. The promotion of mixed stands, the research of complex stand structure, and the increase of management intensity are currently considered as effective management options to reduce forest vulnerability (Puettman 2011; Seidl et al. 2011a). Indeed, heterogeneous forests are expected to be more resilient, thanks to uneven-aged structures allowing the permanence of high regeneration cover in the stand (O'Hara 2006; Cordonnier et al. 2008) and to complementarities in species sensitivity or response to disturbance (DeClerck et al. 2006; Jactel and Brockerhoff 2007). Moreover, growing stock, old median age, and presence of large trees are expected to increase the vulnerability of 
European forests to wind, fire, and bark beetles (Seidl et al. 2011c). Limiting forest stocking through more intensive management (e.g., increasing harvested volumes, increasing cutting frequency, or lowering harvesting diameter) is currently considered as an adaptation measure to reduce forest vulnerability (Legay et al. 2007; Puettman 2011) by limiting competition for water (Sohn et al. 2012) and exposure time to risk (Loisel 2011).

Uneven-aged management of heterogeneous forests has long been applied to maintain continuous cover in European mountain forests dominated by Norway spruce, European fir, and European beech (Schütz 1997; O'Hara et al. 2007). However, this type of silviculture is difficult to carry out because managers shall combine harvesting, thinning, and stand renewal in a single operation. Past management of montane forests has often been too conservative and has led to high stocking levels (O'Hara et al. 2007), to a loss of uneven-aged structures and, in the case of spruce-fir forests, to the replacement of spruce by fir when available light was not sufficient for spruce seedlings (Diaci and Firm 2011). Forest managers are therefore looking for effective management practices that combine lower stock levels, higher spruce regeneration, and long-term persistence of the complex stand structure.

Two management options are currently considered to reach these objectives: (1) increasing harvesting intensity; (2) creating gaps through group selection harvesting. However, if conducted dramatically, these options can have adverse effects: by modifying stand structure and the amount of light reaching the soil, they may disturb the regeneration process. A quantified approach of the effects of these management options on forest dynamics is then necessary to help managers defining silviculture guidelines.

Dealing with management issues requires long-term experiments to assess the effects of different silvicultural practices on forest functions. Field experiments are however long and complex in forest (Ganio and Puettmann 2008), due to long revolution periods, to difficult control of environmental parameters, and to laborious monitoring work. Current experimental stakes thus consist in using forest simulation models as experimental support (Peng 2000; Pretzsch et al. 2008) to assess and compare different management strategies (Söderbergh and Ledermann 2003; Andersson et al. 2005). Indeed, it enables long-term simulation experiments testing several parameters, with good control of fixed factors and the ability to do numerous repetitions.

We used Samsara2, an individual-based and spatially explicit forest dynamics model developed for spruce-fir mountain forests and implemented in the Capsis4 simulation platform (Dufour-Kowalski et al. 2012). Moreover, the simulation of uneven-aged management in an automatic way during long-term experiments required the use of a management model. In such cases, the rules for harvesting and thinning operations are often formulated through a silviculture algorithm (Söderbergh and Ledermann 2003). Among existing silviculture algorithms adapted to uneven-aged management, few are spatially explicit and we found none allowing the simultaneous assessment of the relative effects of varying group sizes and harvesting intensities (Arii et al. 2008; Bohn et al. 2011). Besides, this study was the opportunity to develop an original and multi-objective algorithm, which can be used to simulate a large variety of unevenaged management strategies.

Our objectives in this paper were to present this management model and then to apply it in the case of an uneven-aged spruce-fir forest, to assess the effects of group selection and harvesting intensity on stand heterogeneity and wood production. We hypothesized that increasing the size of gaps created by group selection practices would enhance natural regeneration $\left(\mathrm{H}_{1.1}\right)$, increase size diversity $\left(\mathrm{H}_{1.2}\right)$, and promote spruce maintenance $\left(\mathrm{H}_{1.3}\right)$. As regards harvesting intensity, we hypothesized that tree size diversity would be reduced when increasing the proportion of large trees harvested $\left(\mathrm{H}_{2.1}\right)$. By allowing more light to reach the soil, it would also enhance global natural regeneration $\left(\mathrm{H}_{2.2}\right)$, and especially spruce's, which would be better maintained in the stand $\left(\mathrm{H}_{2.3}\right)$.

\section{Material and methods}

\subsection{Samsara2 forest dynamics model}

Samsara2 is an individual-based and spatially explicit simulation model, developed to simulate forest dynamics (regeneration, growth, and mortality) in mixed and unevenaged mountain forests. Competition for light is calculated within a stand, based on light ray interception by tree crowns (Courbaud et al. 2003). Total height, crown base height, and crown base radius depend on diameter at breast height (dbh) by allometric equations (Vieilledent et al. 2010). Annual diameter increments of individual trees depend on their size and on the amount of light intercepted by their crown during the growing season. Individual effects modulate tree growth to represent the variability of individual tree response to light (Vieilledent et al. 2010). Natural mortality depends on tree dbh and on a competition index defined as the basal area of neighboring trees larger than the subject tree within a radius of $15 \mathrm{~m}$. Seeds are produced by adult trees in relation to their basal area and dispersed randomly within the stand. Seedling germination, growth, and survival depend on the light reaching the ground, calculated in the center of $25 \mathrm{~m}^{2}$ cells. Seedling survival probability increases with light up to an optimum at intermediate levels of light, then decreases for higher levels of light to consider the competition by understory vegetation. Seedlings are transformed into trees, with a crown participating to light interception, when they 
reach the dbh thresholds of $7.5 \mathrm{~cm}$. Every process in the model have been calibrated empirically for silver fir (Abies $a l b a$ ) and Norway spruce (Picea abies) stands, within the montane elevation belt of the Northern French Alps, using a combination of permanent plots located in the Savoy region (for light, allometries, growth, and recruitment (Vieilledent et al. 2010)), French National Forest Inventory data (mortality) and experimental data (seedling response to light, adapted from Burschel et al. (1992)).

The key process of Samsara2 is competition for light, which is considered as the main driver of uneven-aged forest dynamics (Schütz 1997). Other environmental factors are taken into account only indirectly, through the values of model parameters. This approach is consistent with the main goal of the model: assess the effects of management on stand dynamics in a given ecological context (for which the model is specifically calibrated). Samsara2 has indeed been designed for ecological engineering purposes, from fundamental or applied research to management training and discussion support. The model is currently used by the French National Forest Office in training courses on coniferous mountain forest silviculture. Samsara2 is implemented in the simulation platform Capsis4 (Dufour-Kowalski et al. 2012), which enables long-term simulation of management scenarios (Courbaud et al. 2001; Cordonnier et al. 2008).

The reliability of the predictions made with Samsara2 in the ecological context of this study has been evaluated against historical data of Queige forest (Savoy; Courbaud et al., in preparation). The initial state of several stands has been reconstructed from old inventories. Samsara2 was then used to simulate stand dynamics, while past management of each stand was reconstructed using the NVthinner algorithm (Lafond et al. 2012). After about 50 years, the predicted stand structures and compositions were compared to those observed in the field by inventories. The prediction bias have been discussed with French forest managers and judged acceptable considering the incertitude on field inventories data used in management planning (e.g., for basal area: the mean bias equaled $+4.4 \mathrm{~m}^{2} /$ ha, while the mean standard error of observed values was $3.2 \mathrm{~m}^{2} / \mathrm{ha}$ ).

\subsection{Uneven-aged management algorithm}

The uneven-aged management algorithm (UMA) is a management model designed to simulate the complex decision process required in uneven-aged forest management, i.e., the simultaneous combination, at each rotation period, of multiple silvicultural operations including harvesting of mature trees, thinning of small and medium trees, enhancement of natural regeneration, and control of stand structure and composition. The UMA can be combined to individualbased and spatially explicit forest dynamics models and is currently implemented on the simulation platform Capsis4.
It has been developed in collaboration with the French Forest National Office (ONF) and partly based on a silviculture guide (Gauquelin and Courbaud 2006), so as to fit the criteria and decision process used by managers during the thinning and harvesting operations. It requires the definition of 14 parameters (Table 1) related to practical management drivers. The UMA operations are briefly described in the following paragraphs and more details are given in the electronic supplementary materials (Online resource 1).

Starting from the list of all trees present in the stand at the cutting date, the UMA creates two selection lists (one for harvesting, one for thinning), using the diameter limits and biodiversity conservation parameters defined by the user (Table 1). With the default parameters values, the "thinning list" contains trees whose dbh is between 27.5 and $52.5 \mathrm{~cm}$, and the "harvesting list" contains trees whose dbh is larger than $52.5 \mathrm{~cm}$ (parameters Thinning diameter and Harvesting diameter). A relative cutting probability is attributed to each tree depending on individual properties and weights accorded by the user to species mix (at stand scale), tree size, and local density around the tree (parameters Species proportion power and Local density power, see Online resource 1). With the default parameter values, higher cutting probabilities are assigned to the largest trees. In the case of group selection (non-null Aggregation area), the trees located in the densest circle-shaped areas (of size corresponding to the parameter Aggregation area) within the stand are assigned the highest cutting probabilities. If the Species proportion power has a positive non-null value, the trees of the dominant species are assigned higher cutting probabilities. This option can be interesting to drive the species composition balance, but was not used in this study. These probabilities are finally used to rank the two selection lists using a weighted random selection.

At each rotation period in a simulation, the decision to launch the cutting process depends on whether basal areas in the two selection lists are sufficient to make profitable interventions without destabilizing the stand. Maximum quantities allowed to be cut in each list are regulated by two parameters (Harvesting proportion and Thinning proportion). The UMA algorithm computes the quantities available for harvest (Harvesting proportion $\times$ basal area in the harvesting list) and for thinning (Thinning proportion $\times$ basal area in the thinning list). If these quantities are sufficient, trees are cut first in the harvesting list and then in the thinning list, to reach one of the three possible quantities (parameters Minimum, Standard, and Maximal quantities to cut; see Table 1), which define three different cutting intensities.

After these preliminaries, the UMA finally launches the harvesting and thinning operations, using the two selection lists, the quantity to cut determined before and spatialization parameters (cf. Table 1). With the default values, an individual 
Table 1 Overview of the input parameters for the uneven-aged management algorithm (UMA)

\begin{tabular}{|c|c|c|c|}
\hline Type & Parameter & Default value & Short description \\
\hline \multirow[t]{2}{*}{ Diameter limits } & Harvesting diameter & $52.5 \mathrm{~cm}$ & Lower limit for target trees harvesting, upper limit for thinning \\
\hline & Thinning diameter & $27.5 \mathrm{~cm}$ & $\begin{array}{l}\text { Lower limit for aggregates harvesting, thinning, } \\
\text { and dead trees harvesting }\end{array}$ \\
\hline \multirow[t]{3}{*}{ Cutting quantities } & Minimum quantity to cut & $4 \mathrm{~m}^{2} / \mathrm{ha}$ & Lower basal area to cut (profitability limit) \\
\hline & Standard quantity to cut & $6 \mathrm{~m}^{2} / \mathrm{ha}$ & Standard basal area to cut (mean increment) \\
\hline & Maximum quantity to cut & $8 \mathrm{~m}^{2} / \mathrm{ha}$ & Upper basal area to cut (for destocking) \\
\hline \multirow[t]{2}{*}{ Cuttings proportions } & Harvesting proportion & $33 \%$ & $\begin{array}{l}\text { Maximum ratio of basal area to cut, over total basal area designed } \\
\text { for harvesting operation }\end{array}$ \\
\hline & Thinning proportion & $10 \%$ & $\begin{array}{l}\text { Maximum ratio of basal area to cut, over total basal area designed } \\
\text { for thinning operation }\end{array}$ \\
\hline \multirow{2}{*}{$\begin{array}{l}\text { Probability } \\
\text { weightings }\end{array}$} & Species proportion power & 0 & Probability weighting power for species proportion \\
\hline & Local density power & 10 & Probability weighting power for local density \\
\hline \multirow[t]{2}{*}{ Spatialization } & Aggregation area & $0 \mathrm{~m}^{2}$ & Maximum cutting aggregation area for harvesting operation \\
\hline & Buffer distance & $5 \mathrm{~m}$ & Minimum distance between 2 cut trees \\
\hline \multirow{3}{*}{$\begin{array}{l}\text { Biodiversity } \\
\text { conservation }\end{array}$} & Minimum species proportion & $0 \%$ & Threshold to allow cut of the species, in $\%$ of total basal area \\
\hline & Large trees preserved & 0 & Number of large trees preserved for biodiversity \\
\hline & Dead trees harvesting proportion & $0 \%$ & $\begin{array}{l}\text { Maximum proportion of dead trees allowed to be harvested, } \\
\text { over total fresh dead wood basal area }\end{array}$ \\
\hline
\end{tabular}

Default values are based on recommendations from the Mountain silviculture guide designed for Northern French Alps (Gauquelin and Courbaud 2006) or on views exchanged with managers (except for biodiversity conservation parameters, which are not used in this study). These values are those used for the fixed parameters (all excepted Aggregation area and Harvesting proportion) in our simulations

selection harvesting is applied in the harvesting list, respecting a 5-m buffer distance between cut trees (cf. Fig. 1a, c). Gaps of different sizes can be simulated by selecting all trees around a target tree within the area defined by the parameter Aggregation area. The groups are chosen so as to avoid overlapping, and the UMA respects the Buffer distance between groups of cut trees as much as possible (cf. Fig. 1b, d). If the quantity to cut is not reached while respecting these latter constraints, the UMA is allowed to select other trees to complete the cutting. If a thinning is also applied, an individual selection of medium trees is made among trees of the thinning list.

\subsection{Stand initialization}

Before every simulation run, the initialization of Samsara2 requires the user to load a file containing information on the initial stand, including a list of all trees characterized by their species, $\mathrm{dbh}$, and spatial coordinates. As initial stand structure strongly influences simulation results in the short- and long-term (Goreaud et al. 2006), it is important to initialize forest models using realistic stands regarding their composition, size, and spatial structure. We based our simulation study on three stands reconstituted from inventories done in the forest of Queige $\left(45.7^{\circ} \mathrm{N}-6.5^{\circ} \mathrm{E}\right.$, mean altitude $1,400 \mathrm{~m}$, located on a northwest facing slope of about $30^{\circ}$; compartments $n^{\circ} 30,38$, and 39). These three stands were chosen to represent three different diameter structures of uneven-aged forests: two balanced stands enriched either in medium $\left(n^{\circ} 38\right)$ or large $\left(n^{\circ} 39\right)$ trees and an unbalanced stand with a near-even-aged structure characterized by a dense cohort of small and medium trees $\left(n^{\circ} 30\right)$. The simulation results were however very similar for compartments $n^{\circ} 38$ and $n^{\circ} 39$, and compartment $n^{\circ} 30$ quickly converged to similar results too. We therefore decided to present only the simulation results obtained for compartment $n^{\circ} 38$. This stand is dense (basal area $=37.6 \mathrm{~m}^{2}$ ), with a high proportion of mediumsized trees (mean quadratic diameter $=36 \mathrm{~cm}$ ) and a balanced spruce-fir composition (54\% of spruce, in basal area) (Fig. 2a), which is common in the Northern French Alps. The spatial position of trees and the regeneration compartment (saplings and poles, i.e., trees with dbh below $17.5 \mathrm{~cm}$ ) were reconstructed using simulations.

\subsection{Simulations experiments}

We ran three successive simulation experiments: the first one (Exp1) was designed to assess the effect of cutting aggregation, testing a range of values for the parameter Aggregation area; the second and the third ones were designed to assess the effects of harvesting intensity for individual (Exp2) and group selection (Exp3), via the parameter Harvesting proportion. All other parameters of the UMA algorithm were fixed to their default value (Table 1). For both experiments, we studied model responses regarding wood production, stand heterogeneity, and stand regeneration. 

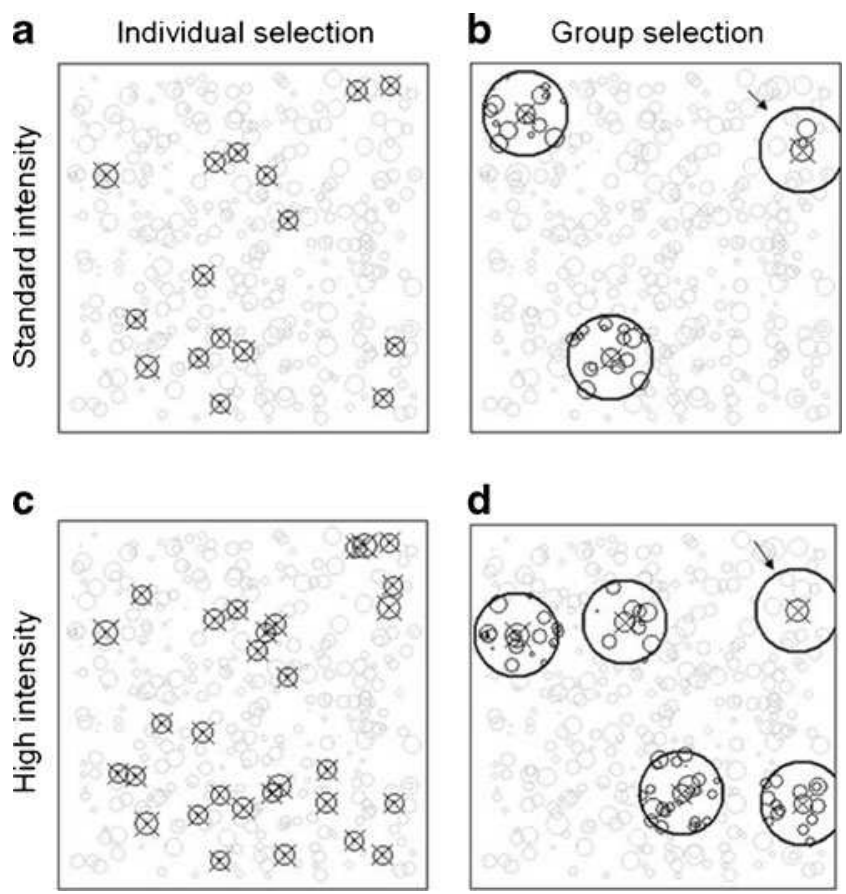

Fig. 1 Examples of cuttings for two different spatial selection types (Aggregation area $=0 \mathrm{~m}^{2}(\mathbf{a}-\mathbf{c})$ and $500 \mathrm{~m}^{2}(\mathbf{b}-\mathbf{d})$ ) and for two different harvesting intensities (Harvesting proportion $=33 \%(\mathbf{a}-\mathbf{b})$ and $100 \%(\mathbf{c}-$ d)). Trees are represented as grey circles of size proportional to their diameter at breast height (dbh). Cut trees appears in black and a cross highlights every target tree: all cut trees are target trees in the case of individual selection (and have been targeted because they were among the largest trees of the stand); whereas for group selection, only the trees which are in the center of a group are target trees (and have been targeted because they were surrounded by large trees). The large circles with a wider line in (b) and (d) symbolize the Aggregation area where all trees are cut around a target tree. The arrows in (b) and (d) point out the final groups cut: the harvesting operation was stopped during the formation of these groups because the target quantity to cut had already been reached

\subsubsection{Cutting aggregation experiment (Exp1)}

We varied the Aggregation area parameter among seven modalities: 0,20 , and $50 \mathrm{~m}^{2}$ for individual and small group selection; 100,500 , and $1,000 \mathrm{~m}^{2}$ for group selection; and $5,000 \mathrm{~m}^{2}$ for large gaps. We thus tested the whole range recommended by the silviculture guide, except for the modality $5,000 \mathrm{~m}^{2}$, which is above the maximum value recommended. We used this last modality to assess a management strategy based on large openings, which are potentially favorable to spruce regeneration (Coates 2002; Grassi et al. 2004).

\subsubsection{Harvesting intensity experiments (Exp2 and Exp3)}

In these experiments, we tested four modalities of the parameter Harvesting proportion, which defined the maximal proportion of trees above $52.5 \mathrm{~cm}$ that could be harvested per rotation: $33,50,75$, and $100 \%$. The modalities 33 and
$50 \%$ gave low and standard harvesting intensities, while 75 and $100 \%$ simulated medium and strong harvesting intensities, respectively. With the strongest modality, the harvesting of large trees $(\mathrm{dbh}>52.5 \mathrm{~cm})$ was thus only limited by the parameter Maximal quantity to cut (see Table 1 and Online Resource 1). The Aggregation area parameter was fixed to $0 \mathrm{~m}^{2}$ for individual selection (Exp2) and to $500 \mathrm{~m}^{2}$ group selection (Exp3).

\subsubsection{Other simulation characteristics}

Simulation length was set to 150 years in order to study the long-term effects of a given treatment (approximate length of the revolution period in such forests). We extracted data each 50 years to analyze the temporal evolution, referenced further as $t_{50}, t_{100}$, and $t_{150}$.

For both simulations, the rate of natural mortality for trees with $\mathrm{dbh} \geq 27.5 \mathrm{~cm}$ was set to zero, in order to avoid random noise caused by the disappearance of trees other than those selected by the UMA algorithm. This choice restricts the results to the context of intensive forest management: small trees died because of individual competition (self-thinning) but large trees were considered to be systematically harvested before their natural death.

Stand area was 4 ha, which was a compromise between the size required to simulate large openings and computing time ( $25 \mathrm{~min}$ for each 150 years simulation). Five repetitions were done for each combination of modalities in the three simulation experiments (seven modalities for the first one and four for the second and third ones).

We fixed parameter values using management recommendations from the Northern Alps silviculture guide (Gauquelin and Courbaud 2006). Following this guide, we also set the intervention frequency to 10 years. Thus, except for the cases of high harvesting intensity and large openings (maximal Harvesting proportion $=75$ and $100 \%$ and Aggregation area $=5,000 \mathrm{~m}^{2}$ ), we simulated the type of management which is currently recommended for fir-spruce production forests in the French Alps: priority to harvest of large trees, low level of thinning in medium size trees, and $15-30 \%$ of total basal area cut per rotation.

\subsubsection{Output variables}

We used several indices to describe stand heterogeneity at different temporal scales:

- Basal area (alive G, $\mathrm{m}^{2} / \mathrm{ha}$ ), as a measure of stand density and living stock

- Proportion of large trees $(\mathrm{dbh}>42.5 \mathrm{~cm})$ after cutting (large tree proportion, $\%$ of total basal area) 


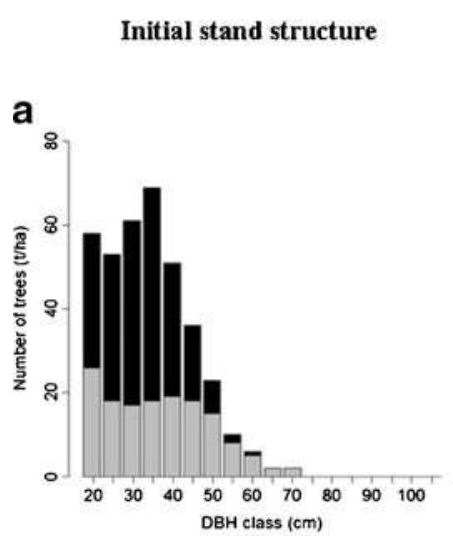

Fig. 2 Evolution of stand diameter distribution under different management scenarios. This figure shows the initial diameter distribution (a) and its state after 50 years of simulation under four different management scenarios (b to e) mixing two cutting aggregation
Stand structure after 50 years of simulation
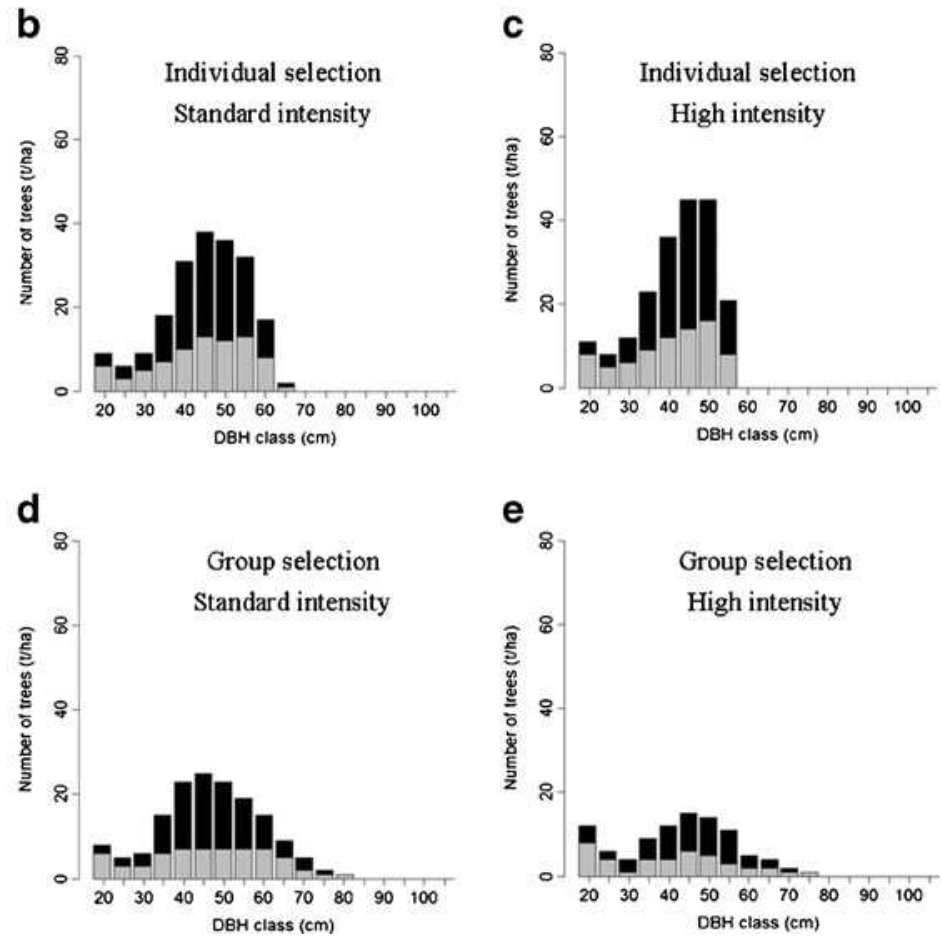

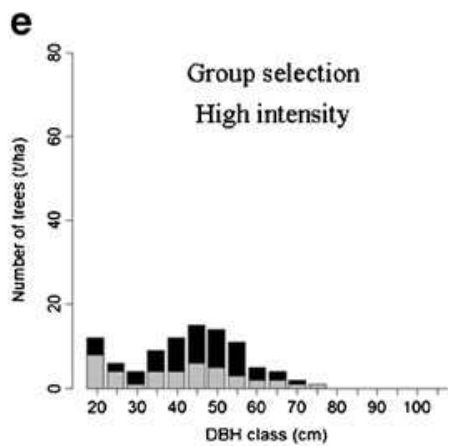

modalities $\left(0\right.$ and $500 \mathrm{~m}^{2}$, respectively for individual and group selection) and two harvesting intensity modalities (33 and $100 \%$, respectively for standard and high intensity). The number of trees per $5 \mathrm{~cm}$ diameter class appears in black for fir and in grey for spruce

- Density of poles (pole density, number of stems/ha), trees with dbh in the range $7.5-17.5 \mathrm{~cm}$

- Gini index, computed on basal area (alive Gini G, no unit):

$$
G=\frac{\sum_{i=1}^{N} \sum_{j=1}^{N}\left|g_{j}-g_{i}\right|}{2 \times \sum_{i=1}^{N} g_{i}}
$$

Where $g_{i}$ is the basal area of the tree $\mathrm{i}$ and $N$ is the total number of trees. This index was used to assess the diversity of tree size in the stand. It is often used to classify forest structure (O'Hara et al. 2007; Duduman 2011). It is generally strongly correlated with the coefficient of variation of diameters (Duduman 2011) but it was proven to have better performances than other diversity indices to describe forest structure (Valbuena et al. 2012).

- Clark-Evans aggregation index (Clark Evans Index (CE), no unit):

$$
\mathrm{CE}=\frac{\bar{r}}{0.5 \times \sqrt{\frac{A}{N}}}
$$

Where $\bar{r}$ is the mean distance to nearest neighbor, $A$ is the stand area, and $N$ is the total number of trees. This index gives information about spatial distribution of trees. Regular distributions have an index higher than 1, aggregated distributions are characterized by values lower than 1 and random distributions will have an index close to 1 (Clark and Evans 1954).

- Spruce ratio among adult trees (tree spruce ratio, \% of total basal area)

- Spruce ratio among poles (pole spruce ratio, $\%$ of pole density)

Except for indices computed on poles, only adult trees (DBH $\geq 17.5 \mathrm{~cm}$ ) were considered for index calculation. Terms between brackets correspond to variable name in graphics (Figs. 3 to 5) and unit used.

We described the characteristics of harvests resulting from the different scenarios by:

- Mean total volume cut per rotation (cut volume, $\mathrm{m}^{3} / \mathrm{ha}$ ): gives the mean volume cut per decade, which is a common measure used by forest managers to assess timber production. 
- Quadratic mean diameter of harvested trees (cut $\mathrm{Dg}, \mathrm{cm})$ : a measure of the size of harvested products (timbers).

The harvesting indices are computed on all cut trees, without distinction between thinning and harvesting, and correspond to the average cut made from the beginning of the simulation (e.g., for date $t_{100}$, indices values are the means computed on the ten first cuttings).

\subsubsection{Result analysis}

The main objective was to compare management modalities among themselves (group selection vs individual selection; high intensity vs standard intensity) and their relative effects on the nine output variables. The temporal analysis aimed at checking the results at different time scales, and was of secondary importance compared to the management modalities in this study. All results are therefore presented with the management modalities in abscises (Aggregation area gradient for Exp1; Harvesting proportion for Exp2 and Exp3) and the temporal evolution is shown with different symbols in the graphics. Although we had only five repetitions, we assumed a normal distribution for output variable values and we used Tukey's test to carry out multi-comparison between the mean values obtained for each management modalities and detect significant differences (confidence level $=0.05$ ) at a same date (data with the results of these tests are available in the Online Resource 2).

\section{Results}

\subsection{Cutting aggregation experiment (Exp1)}

\subsubsection{Effect on living stock}

We observed a decrease of basal area for all management scenarios (Fig. 3a): the initial stand was dense and was automatically destocked by the UMA algorithm. The destocking phenomenon was slightly faster as we increased the size of the cutting aggregation areas. However, the basal area remained in the range $20-35 \mathrm{~m}^{2} /$ ha throughout the simulation and was close to $30 \mathrm{~m}^{2} /$ ha for all aggregation modalities at $t_{150}$.

The proportion of large trees in the stand increased from $40 \%$ to more than $60 \%$ between $t_{0}$ and $t_{50}$ for all modalities, as the numerous medium trees of the initial stand reached maturity. This tendency was amplified by group selection (Fig. 3b) in the short-term (more than $70 \%$ for group sizes above $500 \mathrm{~m}^{2}$ ), as more large trees were left in the stand (Fig. $2 b$ and d). This effect then gradually disappeared and the proportion of large trees tended to stabilize in the range $50-60 \%$ for all modalities at the end of the simulation.

\subsubsection{Effect on regeneration}

There was a significant effect of cutting aggregation on regeneration efficiency, detected after 100 years of simulation (Fig. 3c): group selection cutting enhanced pole abundance. Maximum pole abundance was obtained for the aggregation modality $500 \mathrm{~m}^{2}$ (around 800 stems/ha at $t_{150}$ ). We observed significant lower values for the modality $5,000 \mathrm{~m}^{2}$, though pole density was still high (560 stems/ha on average).

\subsubsection{Effect on heterogeneity}

Cutting aggregation had a significant effect on stand structure diversity (Fig. 3d and e). The Gini index increased with the size of cutting aggregation areas (Fig. 3d), from 0.38 for individual selection to 0.5 for large openings (at date $t_{100}$ ). The temporal analysis (not shown) indicated that, in all cases, the value of the Gini index remained almost constant after approximately 100 years. Because of the preservation of large trees during long periods in the case of group selection, the Gini index may have been highly impacted by the presence of very large trees, leading to a potential overestimation of group selection benefits. We therefore checked the diameter distributions at the end of the simulations and found few very large trees (dbh 90$190 \mathrm{~cm}$ ). Moreover, we computed the relative difference between the Gini index value calculated on all trees and the one calculated on a restricted list excluding very large trees (data not shown). It appeared that this relative difference was always less than $5 \%$, which is low compared to the relative difference between Gini index obtained for group and individual selection (about $25 \%$ ). We concluded that the differences observed between individual and group selection systems was really significant.

Group selection practices also modified spatial structure (Fig. 3e), with the creation of aggregated structures resulting from cohorts of trees initialized by canopy openings (Clark-Evans index $<1$ ).

Group selection had few effects on composition. Although spruce was well represented in the short-term (around 53$60 \%$ of total basal area), its ratio strongly decreased over time, to reach $25 \%$ at the end of the simulations for all modalities (Fig. 3f). Group selection had no effect on the proportion of spruce within the regeneration (Fig. $3 \mathrm{~g}$ ): we observed the same low spruce ratio in poles (21-24\% at date $\left.t_{150}\right)$ whatever the size of cutting aggregation areas.

\subsubsection{Effect on wood production}

The global mean harvested volume was not much impacted by the aggregation areas (Fig. 3h). The only significant difference was observed for modality $5,000 \mathrm{~m}^{2}$ but was related to a very slight decrease of mean cut volume ( $\max 3 \mathrm{~m}^{3} / \mathrm{ha}$ ). 

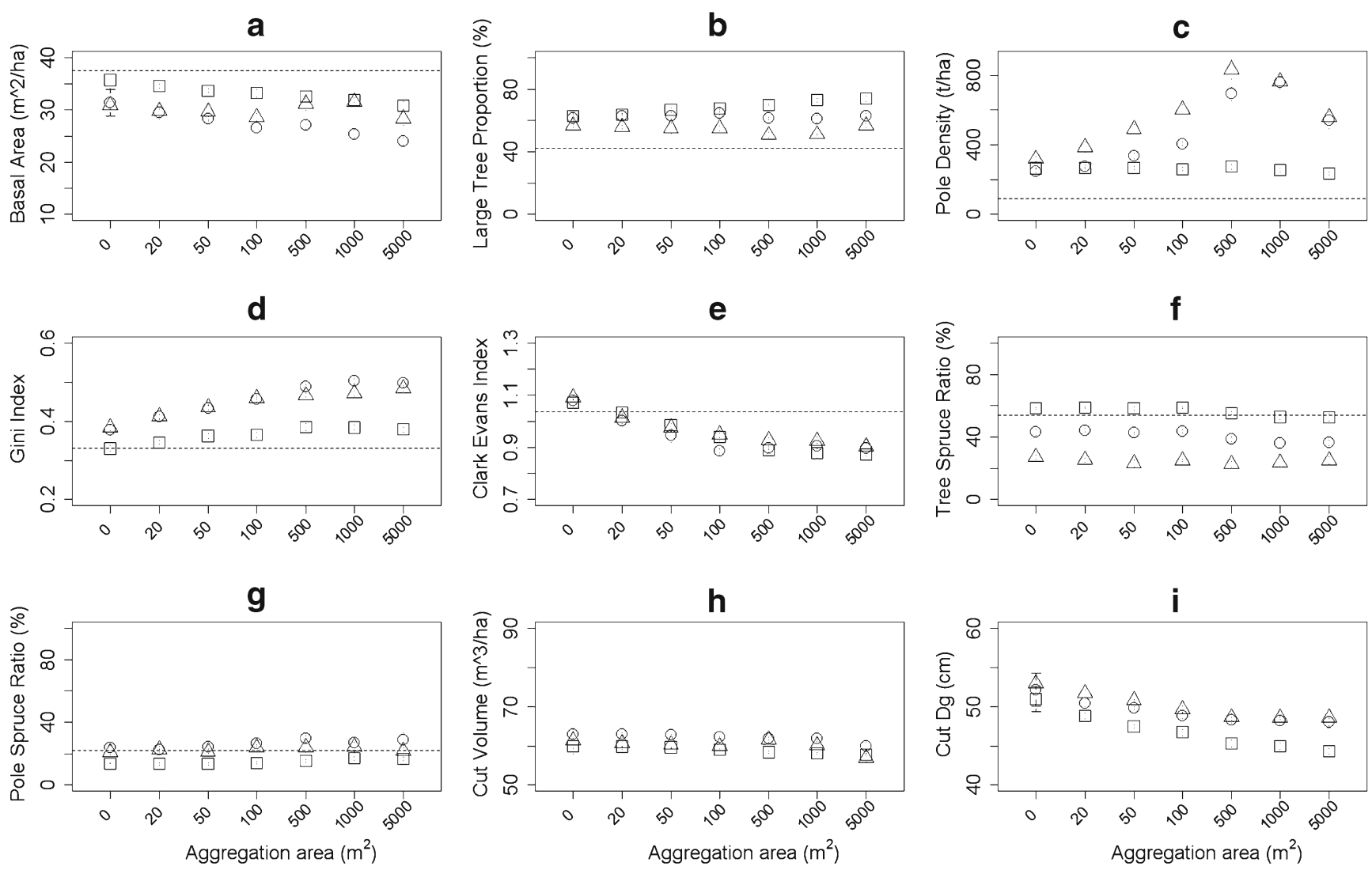

Fig. 3 Effect of group size on stand production and heterogeneity, at different time scales. Here are presented nine indicators describing the simulation results obtained for the cutting aggregation experiment (Exp1). Each plot gives the relation between the Aggregation area parameter modalities ( $x$ axis) and one stand indicator ( $y$ axis), as observed after 50 years (squares), 100 years (circles), and 150 years

Group selection practices had however a significant effect on the type of product harvested, as indicated by lower quadratic mean diameters of cut trees (Fig. 3i). This is especially true at $t_{50}$, where individual selection cutting targeted the largest trees of the stand $(\mathrm{Dg}=50 \mathrm{~cm})$, whereas trees harvested by group selection were significantly smaller $(\mathrm{Dg}=45 \mathrm{~cm})$. Indeed, although groups were established in the densest zones (i.e., containing numerous large trees), these aggregated cuts also included some medium and small trees, which led to more diverse products than for individual selection, thus reducing the quadratic mean diameter of cut trees. The long-term effect was smaller but still significant.

\subsection{Harvesting intensity experiments (Exp2 and Exp3)}

\subsubsection{Effect on living stock}

As for the cutting aggregation experiment, we observed a destocking phenomenon, which was here reinforced by higher management intensities. Stand basal areas (triangles), compared to initial values (dotted lines). a and $\mathbf{b}$ give information about living stock, $\mathbf{c}$ about regeneration, $\mathbf{d}$ to $\mathbf{g}$ about heterogeneity, and $\mathbf{h}$ and $\mathbf{i}$ about wood production. Each point represents the mean value calculated on the five simulations done for the given silvicultural modality, and error bars represents one standard deviation

decreased with harvesting proportion, but the speed and intensity of this destocking effect depended on cutting aggregation. For individual selection cutting (Exp2, Aggregation area $=0 \mathrm{~m}^{2}$ ), differences between extensive management (Harvesting proportion=33\%) and other modalities were low (about $2.5-3.5 \mathrm{~m}^{2} / \mathrm{ha}$ ) but significant (Fig. 4a). Differences between "intensive" modalities were not significant. For group selection cutting (Exp3, Aggregation area $=500 \mathrm{~m}^{2}$ ), differences between intensity treatments (Fig. 5a) were stronger than for individual selection (from 3 to $7 \mathrm{~m}^{2} /$ ha higher) and generally significant. Basal areas oscillated over time: for each modality, values were very close at $t_{50}$ and $t_{150}$, but lower at $t_{100}$.

As for Exp1, the proportion of large trees increased in the short-term for both Exp2 and Exp3 (Figs. 4b and $5 b)$. However, this increase was limited by harvesting intensity in the case of individual selection (Exp2, Fig. 4b), with values close to the recommendations made by Gauquelin and Courbaud (2006) for production forests $(40-50 \%$ of large trees in the stand after 
cut). In the case of group selection (Exp3, Fig. 5b), harvesting intensity had no effect on the initial increase of large tree proportion, but had strong effects at $t_{100}$ : the proportion of large trees fell to 35 and $27 \%$ for the two most intensive modalities. This effect was however punctual, as the proportion of large trees increased above $40 \%$ at $t_{150}$ and was then not significantly different from the value obtained with a maximum harvesting proportion of $50 \%$.

\subsubsection{Effect on regeneration}

Harvesting intensity had no significant effect on regeneration in individual selection scenarios (Exp2, Fig. 4c): pole density increased over time for all harvesting intensities and reached 340-360 stems/ha in the long-term. For group selection scenarios (Exp3, Fig. 5c), we observed a low but significant positive effect of harvesting intensity in the short-term. This effect was reversed in the long-term, with a strong negative effect of harvesting intensity on regeneration. Though, the final pole density was still important for all modalities and larger than for individual selection scenarios (500-850 stems/ha against a maximum of $360 \mathrm{stems} / \mathrm{ha}$ for individual selection).

\subsubsection{Effect on stand heterogeneity}

Harvesting intensity had contrasted effects on stand structure. On one hand, it lowered diameter diversity, with a slight but significant negative effect of harvesting intensity in the case of individual selection (Exp2, Fig. 4d). For group selection scenarios, harvesting intensity had a greater negative effect after 100 years of simulation (Fig. 5d), with Gini index around 0.4 for intensive managements whereas it was almost 0.5 for the modality $33 \%$. However, group selection had more influence than intensity on this size diversity index, as all values in the Exp3 are higher than in the Exp2, whatever the intensity modality.

Harvesting intensity had a null effect on spatial structure in the case of individual selection (Exp2, Fig. 4e) but the two most intensive modalities increased the spatial aggregation of trees when combined to group selection (Exp2, Fig. $5 \mathrm{~d})$, especially at $t_{50}$.
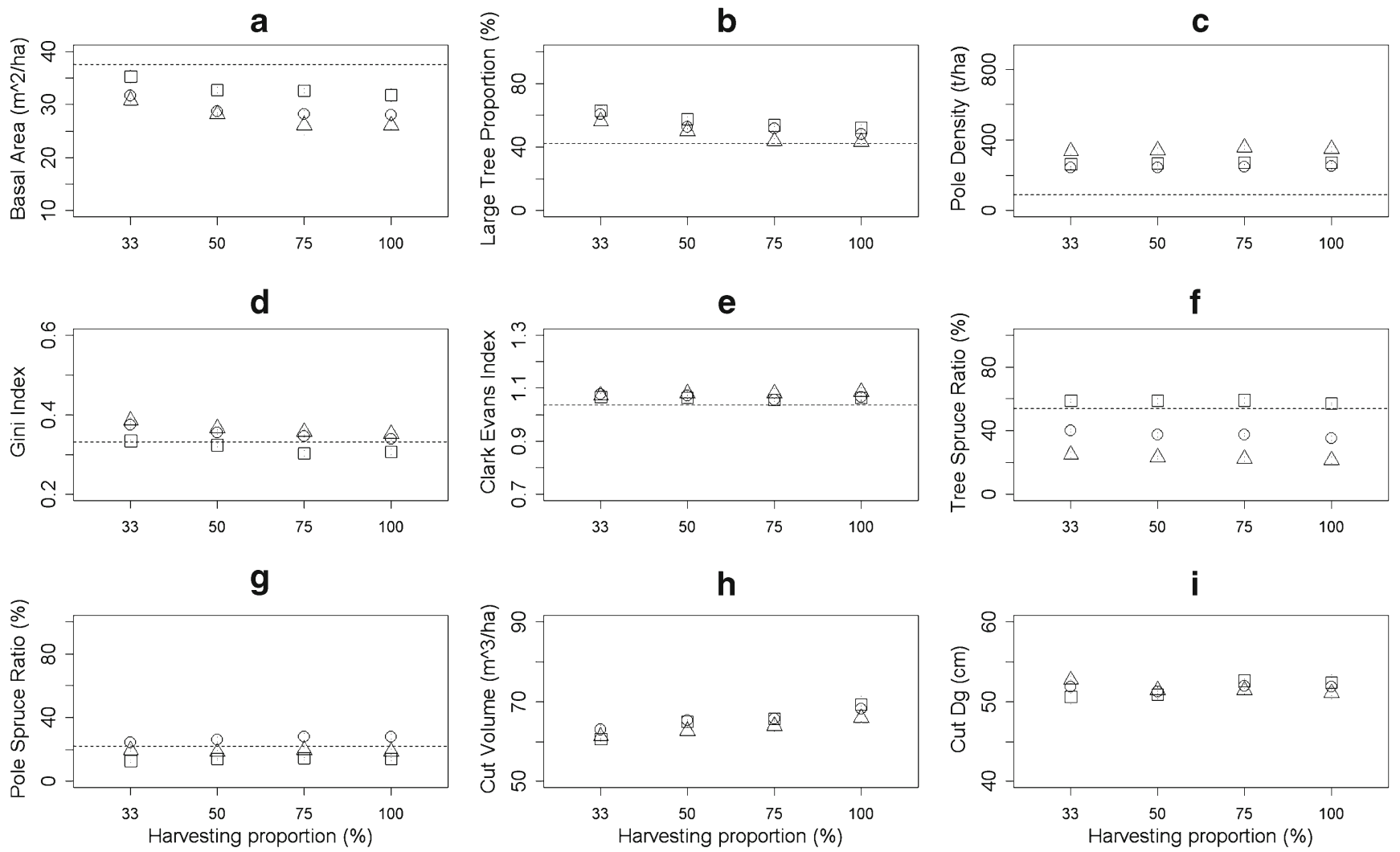

Fig. 4 Effect of harvesting intensity on stand production and heterogeneity at different time scales, in the case of individual selection cutting (group size $=0 \mathrm{~m}^{2}$ ). Here are presented nine indicators describing the results obtained for the harvesting intensity experiment in the case of individual selection cutting (Exp2). Each plot gives the relation between the Harvesting proportion parameter modalities ( $x$ axis) and one stand indicator ( $y$ axis), as observed after 50 years (squares), 100 years (circles), and 150 years (triangles), compared to initial values (dotted lines). a and $\mathbf{b}$ give information about living stock, $\mathbf{c}$ about regeneration, $\mathbf{d}$ to $\mathbf{g}$ about heterogeneity, and $\mathbf{h}$ and $\mathbf{i}$ about wood production. Each point represents the mean value calculated on the five simulations done for the given silvicultural modality, and error bars represents one standard deviation 

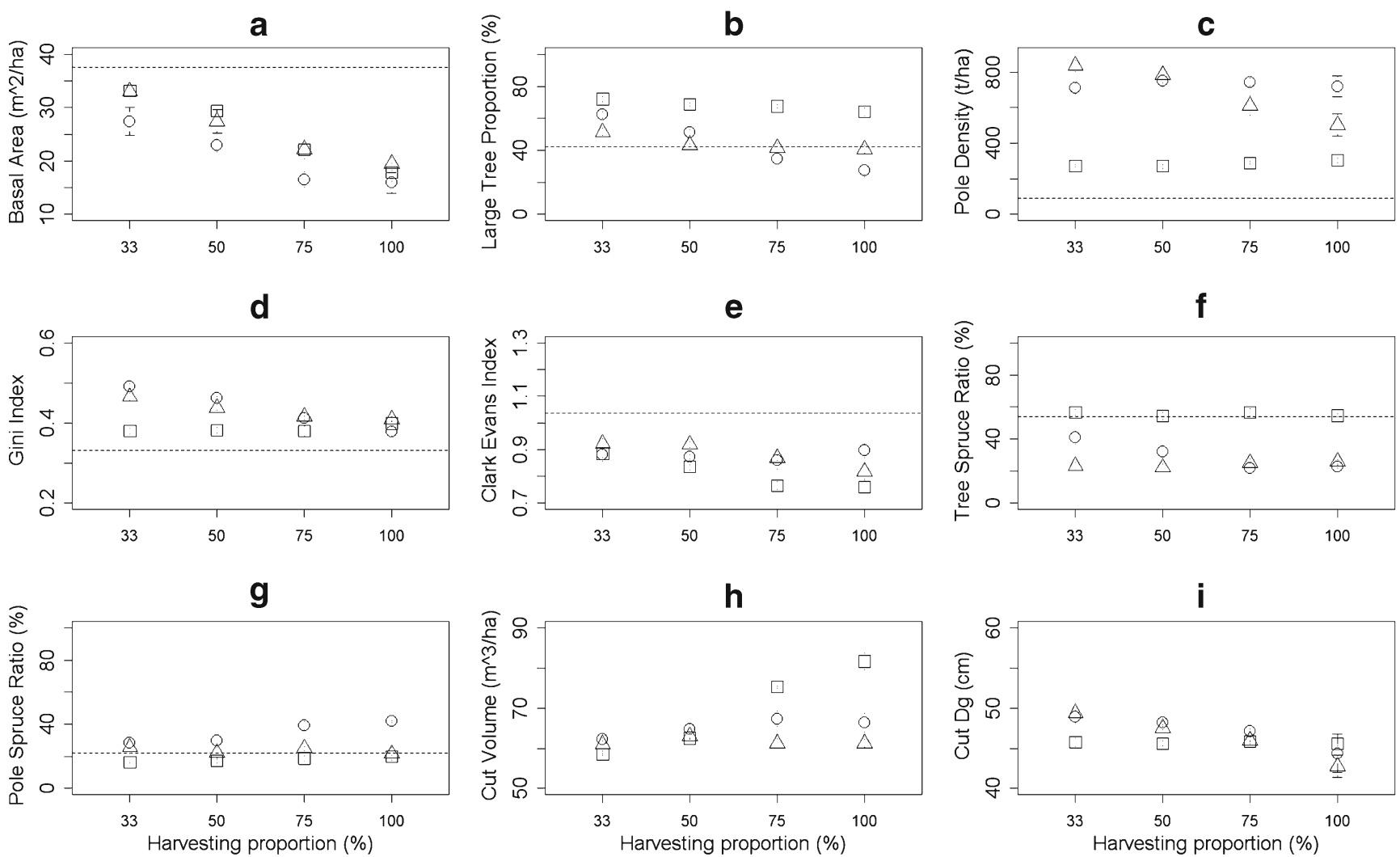

Fig. 5 Effect of harvesting intensity on stand production and heterogeneity at different time scales, in the case of group selection cutting (group size $=$ $500 \mathrm{~m}^{2}$ ). Here are presented nine indicators describing the results obtained for the harvesting intensity experiment in the case of group selection cutting based on aggregation areas of $500 \mathrm{~m}^{2}$ (Exp3). Each plot gives the relation between the Harvesting proportion parameter modalities ( $x$ axis) and one

Spruce proportion decreased over time for all management scenarios (Figs. 4f and 5f) from almost $60 \%$ to less than $25 \%$. Overall, harvesting intensity had little effect on stand composition. In the case of individual selection (Exp2), harvesting intensity had only slight effects on adult spruce proportion (Fig. 4f) and on pole spruce ratio (Fig. 4g). The latter oscillated between 13 and $28 \%$ over time. In the case of group selection (Exp3), we observed that the transition between the dates $t_{50}$ and $t_{150}$ was accelerated by harvesting intensity, as showed by the significant differences at $t_{100}$ between the two most intensive modalities (about $22 \%$ ) and classical management (41\%). Spruce regeneration (Fig. $5 \mathrm{~g}$ ) was however significantly enhanced by the two most intensive modalities during 100 years (about $40 \%$ of poles, against $29 \%$ for standard management at this date), due to low basal areas (Fig. 5a) and numerous canopy openings. This effect was however not maintained in the long-term $\left(25 \%\right.$ in all cases at $\left.t_{150}\right)$, as there were less harvests after 100 years (Fig. 5h) and therefore higher living stocks (Fig. 5a). stand indicator ( $y$ axis), as observed after 50 years (squares), 100 years (circles), and 150 years (triangles), compared to initial values (dotted lines). $\mathbf{a}$ and $\mathbf{b}$ give information about living stock, $\mathbf{c}$ about regeneration, $\mathbf{d}$ to $\mathbf{g}$ about heterogeneity, and $\mathbf{h}$ and $\mathbf{i}$ about wood production. Each point represents the mean value calculated on the five simulations done for the given silvicultural modality, and error bars represents one standard deviation

\subsubsection{Effect on wood production}

As expected, the mean volume cut per rotation was higher for intensive managements in the short-term for individual selection $\left(+8.5 \mathrm{~m}^{3} / \mathrm{ha}\right.$, Fig. $\left.4 \mathrm{~h}\right)$, and more especially for group selection cutting $\left(+23 \mathrm{~m}^{3} / \mathrm{ha}\right.$, Fig. $\left.5 \mathrm{~h}\right)$. However, this positive effect disappeared over time: indeed, with intensive modalities, large trees were quickly harvested and became too scarce to allow regular cutting operations (each 10 years). Therefore, there was no harvesting at all during some rotations, leading to a decrease of the mean cut volume, which returned to levels close to those obtained with classical management $\left(60-65 \mathrm{~m}^{3} / \mathrm{ha}\right)$.

The type of products highly depended on the cutting aggregation strategy. For individual selection cutting, harvesting intensity had little effect on the quadratic mean diameter of cut trees (Fig. 4i), which stayed stable between modalities and over time $(50-53 \mathrm{~cm})$. In the case of group selection harvesting, intensifying management allowed the algorithm to create a higher number of gaps and thus to cut a higher proportion of large trees. It had little effect on product 
diversity in the short-term (Fig. 5i), as a high proportion of large trees was still available (Fig. 5b). It however gradually led to the harvest of smaller trees, especially for the most intensive modality ( $\mathrm{Dg}=42.8 \mathrm{~cm}$, against $49.4 \mathrm{~cm}$ for modality $33 \%$ ), as large trees rarefied after 100 years of simulation (Fig. 5b).

\section{Discussion}

\subsection{Effects of group selection practices on structure diversity}

Our results confirmed that group selection cutting enhances size diversity, as found by Cordonnier et al. (2008). The large array of group sizes tested allowed us to detect small but significant variations of the size diversity indicator. Using the classification realized by Duduman (2011) for the Gini index, we noticed two main trends: for individual selection and small groups, we obtained low irregularity of size structure; on the contrary, medium to large groups selection led to a more diversified size structure with true uneven-sized stands (Duduman 2011). We also observed a threshold around $500 \mathrm{~m}^{2}$, as the Gini index reached a plateau (around 0.5 ). It seems therefore not necessary to create gaps larger than $500 \mathrm{~m}^{2}$ to increase structure irregularity. The positive effect of group selection on diameter diversity was reduced when increasing harvesting intensity. However, in the long-term, stands were still more structurally complex for intensive group selection scenarios than for standard individual selection cutting.

Group selection practices are also interesting for spatial structure, analyzed here by the Clark-Evans index. Individual selection led to random or regular structures $(\mathrm{CE}>1)$, whereas group selection enabled the creation of a more aggregated spatial structure. Such pattern is interesting in our case study, as uneven-aged stands with a small-group horizontal structure are judged well suited to fulfill protection function against natural hazards (Motta and Haudemand 2000; Gauquelin and Courbaud 2006; O'Hara 2006), which is a very important topic in mountain forests. However, the link between spatial structure and resilience has not been clearly demonstrated yet and it is therefore difficult to judge this aspect of the heterogeneity within the context of adaption to climate change.

\subsection{Effects of forest management on species mix}

Although spruce and fir were equally represented in the initial stand, fir systematically dominated the stand at the end of the simulation, whatever the size of cutting groups or harvesting intensities. In the case of individual or small group selection cutting, this result is consistent with field observations: silver fir is a more shade-tolerant species than
Norway spruce and is therefore favored by conservative management (Diaci and Firm 2011). Nevertheless, in the case of group selection, our results do not support our hypothesis $\left(\mathrm{H}_{1.3}\right)$ : aggregated cuttings were not sufficient to efficiently regenerate spruce and maintain a wellbalanced mix in this experiment. Likewise, intensification did not improve spruce regeneration, contrary to our hypothesis $\left(\mathrm{H}_{2.3}\right)$. These results are in contradiction with some field observations done in the Alps (Grassi et al. 2004; Streit et al. 2009; Diaci and Firm 2011), where group selection practices and reduced stocking have proved efficient to enhance spruce regeneration. However, other field studies have shown that gaps are not always sufficient to maintain mid-tolerant species and must be coupled with additional practices, like soil preparation or dead wood conservation in order to create favorable microsites (Webster and Lorimer 2005; Bolton and D'Amato 2011).

This raises the question of the ecological context and modeling options considered in such simulation experiments. We designed this study to deal with management issues encountered in the Northern French Alps, where the question of spruce regeneration is problematical because of very active fir regeneration, especially in north-facing slopes (Gauquelin and Courbaud 2006). As the Samsara2 regeneration module has been calibrated on permanent plots representing this context, our results should not be extrapolated to ecological contexts where spruce is more advantaged (south facing slopes, higher altitude with a colder climate...). Another limit of these simulation experiments is the absence of seed supply from neighboring stands, especially as Norway spruce seeds can spread easily at large distances. This simplification was done to study the effects of management on forest dynamics at stand scale. However, this assumption induced a negative retroaction leading to a gradual disappearance of spruce. In order to further explore the effect of management on the long-term species balance, it may be necessary to reconsider this approximation by introducing a seeds supply from neighboring stands. This would however be more relevant with a landscape approach (Dreyfus 2012).

Since the variations of ground light produced by the different management strategies tested in this study were not sufficient to maintain a well-balanced species mix, it may be interesting to assess other silvicultural operations, such as preservation of spruce seed bearers, more intensive thinnings in young and medium stages or harvesting preferentially the dominant species (Schütz 1997). Three parameters of the UMA algorithm could be used for that purpose (Table 1): the Species proportion power parameter, which gives a higher cutting probability to trees of the dominant species; the Minimum species proportion parameter, which forbids the harvest of trees of the minority species when its relative proportion is below the threshold defined by this 
parameter; and the Thinning proportion parameter, which determines the maximum amount of medium size trees to cut (see Online Resource 1 for more details). By using these parameters, more complex uneven-aged management strategies could be tested in order to better regulate species composition.

\subsection{Sustainable management to adapt forests to climate change}

The initial stand was dense $\left(37.6 \mathrm{~m}^{2} / \mathrm{ha}\right)$, with a high proportion of medium size trees and active fir regeneration. So as to ensure a better adaptation of this stand to climate change, the management objectives were (1) to improve and maintain the complex stand structure, (2) to reduce living stock, while preserving timber production, and (3) to enhance natural regeneration. The uneven-aged silvicultural practices tested in this study (group selection and intensified harvesting) were expected to be efficient management options to meet these objectives (Puettman 2011; Seidl et al. 2011a).

For moderate harvesting intensities (harvest ratio from 33 to $50 \%$ ), basal area values were effectively lowered in the optimal range $\left(20-35 \mathrm{~m}^{2} / \mathrm{ha}\right)$ recommended by Gauquelin and Courbaud (2006) in this context. Considering the initial stand structure, group selection cutting were here particularly well adapted to quickly obtain irregular structures, because more medium size trees were harvested than in individual selection cutting. Besides, increasing harvesting intensity enabled quick stand destocking by decreasing basal area and large tree proportion, but led to too low basal areas in some cases, especially for the most intensive group selection scenarios (about $15 \mathrm{~m}^{2} / \mathrm{ha}$ ).

Intensifying management strongly increased harvested volumes at $t_{50}$, especially for group selection cutting; but these short-term advantages revealed non-sustainable and gradually disappeared. This loss in production was due to the decrease of basal area and large tree proportion, which were insufficient to allow harvesting operations at some dates. Yield was thus very variable over time, which goes against sustainable management objectives.

Natural regeneration was particularly sensitive to group selection, and the creation of medium-size gaps $\left(500 \mathrm{~m}^{2}\right)$ already supplied enough light to efficiently promote regeneration. The values observed for pole abundance are consistent with field observations in the Northern French Alps (Fuhr et al. 2012). The fact that pole density was lower for modality $5,000 \mathrm{~m}^{2}$ is also consistent with observations done in mixed forests of British Columbia (Coates 2002), where the density of seedlings and recruits was lower in large gaps (1,001-5,000 $\left.\mathrm{m}^{2}\right)$, compared to medium ones (301$1,000 \mathrm{~m}^{2}$ ). In the case of the Samsara2 regeneration model, the establishment of fir and spruce saplings is optimum for intermediate light conditions (60\% of full light) but decreases in full light. This is consistent with the natural dynamics observed in montane forests of the intermediate Northern French Alps, where herbaceous or shrubs layers (like blueberry, Vaccinium myrtillus) tend to strongly compete with saplings in large gaps (Grassi et al. 2004; Motta and Haudemand 2000).

\subsection{General management considerations for adaptation to climate change}

Explicit consideration of climate change in simulation experiments is a major challenge, due to the complexity and uncertainties related to climate scenarios and to tree responses (Puettman 2011). Moreover, long-term responses of forests to current management options are hard to foresee, even apart from climate change. Understanding forest responses to alternative management scenarios under constant environmental conditions is thus a first but necessary step, before considering the impact of climate change on forests in interaction with management. This was the aim of this study.

Our simulation results demonstrated the positive impacts of group selection harvesting on diameter diversity. However, without specific management measures such as tending operations, group selection harvesting was not sufficient to maintain a balanced species mix. If the main objective is to reduce living stocks to diminish exposure to climate hazards, an efficient strategy is to increase the proportion of large trees harvested. Cutting groups of large trees even accelerate the process. However, managers should avoid reducing basal area below a critical threshold, around $20 \mathrm{~m}^{2}$ in our ecological context (Gauquelin and Courbaud 2006), in order to maintain a continuous forest cover. For this purpose, it seems judicious to harvest maximum $50 \%$ of the large trees of a stand in a single intervention. Moreover, considering the fact that forest complexity must be maintained to enhance its resilience, managers should be aware that increasing harvesting intensity reduces stand structure diversity, especially in the case of individual selection harvesting.

In conclusion, whenever forests need to be destocked to limit their sensitivity to natural hazards, forest managers should implement group selection practices, for instance with groups of size around $500 \mathrm{~m}^{2}$, with a moderate harvesting intensity (no more than $50 \%$ of large trees harvested per rotation).

Acknowledgments We are grateful to François de Coligny, who gave us some helpful knowledge about the Java language and helped us with the programming work. We also thank Christine Deleuze, Thierry Sardin, Didier François, and Bruno Chopard from the French National Forest Office (ONF) for their collaboration during the algorithm development. Finally, we thank two anonymous reviewers for their valuable comments. 
Funding This work was financially supported by both the GeForHet project ( ${ }^{\circ}$ E23/2010), from the French research program "Biodiversity, Forest Management and Public Policy" (BGF), and by the European Research project "Advanced multifunctional forest management in European mountain ranges” (ARANGE, n² 289437).

\section{References}

Andersson M, Dahlin B, Mossberg M (2005) The forest time machine - a multi-purpose forest management decision-support system. Comput Electron Agric 49:114-128

Arii K, Caspersen JP, Trevor AJ, Sean CT (2008) A selection harvesting algorithm for use in spatially explicit individualbased forest simulation models. Ecol Model 211:251-266

Beniston M, Stephenson DB, Christensen OB, Ferro CAT, Frei C, Goyette S, Halsnaes K, Holt T, Jylha K, Koffi B, Palutikof J, Scholl R, Semmler T, Woth K (2007) Future extreme events in European climate: an exploration of regional climate model projections. Climate Change 81:71-95

Bohn KK, Nyland RD, Yanai RD (2011) Comparing selection system and diameter-limit cutting in uneven-aged northern hardwoods using computer simulation. Can J For Res-Rev Can Rech For 41:963-973

Bolton NW, D'Amato AW (2011) Regeneration responses to gap size and coarse woody debris within natural disturbance-based silvicultural systems in northeastern Minnesota, USA. For Ecol Manag 262:1215-1222

Burschel P, El Kateb H, Mosandl R (1992) Experiments in mixed mountain forests in Bavaria. In: Kelty MJ, Larson BC, Oliver $\mathrm{CD}$ (eds) The ecology and silviculture of mixed-species forests. Kluwer, New York, pp 183-215

Clark PJ, Evans FC (1954) Distance to nearest neighbour as a measure of spatial relationships in populations. Ecology 35:445-453

Coates KD (2002) Tree recruitment in gaps of various size, clearcuts and undisturbed mixed forest of interior British Columbia, Canada. For Ecol Manag 155:387-398

Cordonnier T, Courbaud B, Berger F, Franc A (2008) Permanence of resilience and protection efficiency in mountain Norway spruce forest stands: a simulation study. For Ecol Manag 256:347-354

Courbaud B, Goreaud F, Dreyfus P, Bonnet F (2001) Evaluating thinning strategies using a tree distance dependent growth model: some examples based on the CAPSIS software "uneven-aged spruce forests" module. For Ecol Manag 145:15-28

Courbaud B, De Coligny F, Cordonnier T (2003) Simulating radiation distribution in a heterogeneous Norway spruce forest on a slope. Agri For Meteo 116:1-18

DeClerck FAJ, Barbour MG, Sawyer JO (2006) Species richness and stand stability in conifer forests of the Sierra Nevada. Ecology 87:2787-2799

Diaci J, Firm D (2011) Long-term dynamics of a mixed conifer stand in Slovenia managed with a farmer selection system. For Ecol Manag 262:931-939

Dreyfus P (2012) Joint simulation of stand dynamics and landscape evolution using a tree-level model for mixed uneven-aged forests. Ann For Sci 69:283-303

Duduman G (2011) A forest management planning tool to create highly diverse uneven-aged stands. Forestry 84:301-314

Dufour-Kowalski S, Courbaud B, Dreyfus P, Meredieu C, de Coligny F (2012) Capsis: an open software framework and community for forest growth modelling. Ann For Sci 69:221-233

Fuhr M, Gatel JF, Weyant J, Durand N, Breton V, Favier G (2012) Large gaps dynamics in moutain forests (Northern Alps) - dynamique des grandes trouées en forêt de montagne (Alpes du Nord). Projet INTERREG IV Franco-Suisse FORETS DE PROTECTION/ Action $n^{\circ}$ 3.2.7. Irstea
Ganio LM, Puettmann KJ (2008) Designing long-term, large-scale forestry experiments with research objectives at multiple scales. J Sustain For 26:1-18

Gauquelin X, Courbaud B (2006) Guide des sylvicultures de montagne-Alpes du Nord françaises. Cemagref, CRPF RhôneAlpes, ONF

Goreaud F, Alvarez I, Courbaud B, De Coligny F (2006) Long-term influence of the spatial structure of an initial state on the dynamics of a forest growth model: a simulation study using the Capsis platform. Simulation 82:475-495

Grassi G, Minotta G, Tonon G, Bagnaresi U (2004) Dynamics of Norway spruce and silver fir natural regeneration in a mixed stand under uneven-aged management. Can J For Res-Rev Can Rech For 34:141-149

Jactel H, Brockerhoff EG (2007) Tree diversity reduces herbivory by forest insects. Ecol Lett 10:835-848

Jactel H, Nicoll BC, Branco M, Gonzalez-Olabarria JR, Grodzki W, Langstrom B, Moreira F, Netherer S, Orazio C, Piou D, Santos H, Schelhaas MJ, Tojic K, Vodde F (2009) The influences of forest stand management on biotic and abiotic risks of damage. Ann For Sci 66:701-719

Lafond V, Cordonnier T, De Coligny F, Courbaud B (2012) Reconstructing harvesting diameter distribution from aggregate data. Ann For Sci 69:235-243

Legay M, Mortier F, Mengin-Lecreulx P, Cordonnier T (2007) La gestion forestière face aux changements climatiques : tirons les premiers enseignements. Rendez-vous techniques de l'ONF:95102

Loisel P (2011) Faustmann rotation and population dynamics in the presence of a risk of destructive events. J For Econ 17:235-247

Motta R, Haudemand J-C (2000) Protective forests and silvicultural stability. Mt Res Dev 20:180-187

O'Hara KL (2006) Multiaged forest stands for protection forests: concepts and applications. For Snow Landsc Res 80:45-55

O'Hara KL, Hasenauer H, Kindermann G (2007) Sustainability in multi-aged stands: an analysis of long-term plenter systems. Forestry 80:163-181

Peng C (2000) Understanding the role of forest simulation models in sustainable forest management. Environ Impact Assess Rev 20:481-501

Pretzsch H, Grote R, Reineking B, Rotzer T, Seifert S (2008) Models for forest ecosystem management: a European perspective. Ann Bot 101:1065-1087

Puettmann KJ (2011) Silvicultural challenges and options in the context of global change: "simple" fixes and opportunities for new management approaches. J For 109:321-331

Schütz JP (1997) Silviculture 2. Management of irregular and mixed stands-sylviculture 2. La gestion des forêts irrégulières et mélangées. Gérer l'environnement. Presses polytechniques et universitaires romandes, Lausanne, Switzerland

Seidl R, Rammer W, Lexer MJ (2011a) Adaptation options to reduce climate change vulnerability of sustainable forest management in the Austrian Alps. Can J For Res 41:694-706

Seidl R, Rammer W, Lexer MJ (2011b) Climate change vulnerability of sustainable forest management in the Eastern Alps. Climate Change 106:225-254

Seidl R, Schelhaas MJ, Lexer MJ (2011c) Unraveling the drivers of intensifying forest disturbance regimes in Europe. Glob Chang Biol 17:2842-2852

Söderbergh I, Ledermann T (2003) Algorithms for simulating thinning and harvesting in five European individual-tree growth simulators: a review. Comput Electron Agric 39:115-140

Sohn JA, Kohler M, Gessler A, Bauhus J (2012) Interactions of thinning and stem height on the drought response of radial stem growth and isotopic composition of Norway spruce (Picea abies). Tree Physiol 32:1199-1213 
Streit K, Wunder J, Brang P (2009) Slit-shaped gaps are a successful silvicultural technique to promote Picea abies regeneration in mountain forests of the Swiss Alps. For Ecol Manag 257:19021909

Valbuena R, Packalen P, Martin-Fernandez S, Maltamo M (2012) Diversity and equitability ordering profiles applied to study forest structure. For Ecol Manage 276:185-195
Vieilledent G, Courbaud B, Kunstler G, Dhote J-F, Clark JS (2010) Individual variability in tree allometry determines light resource allocation in forest ecosystems: a hierarchical Bayesian approach. Oecologia 163:759-773

Webster CR, Lorimer CG (2005) Minimum opening sizes for canopy recruitment of midtolerant tree species: a retrospective approach. Ecol Appl 15:1245-1262 